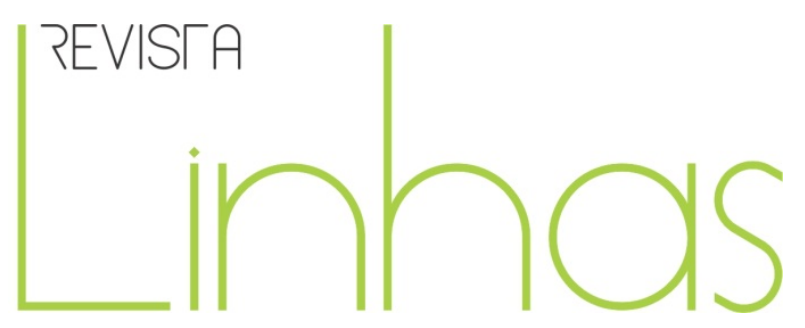

\title{
Avanços na inclusão da temática de história e cultura afro- brasileira e africana. PNLD Ensino Médio 2012 e a lei 10.639
}

\begin{abstract}
Resumo
A questão principal deste artigo é verificar a aplicação da lei 10.639 que incluiu no currículo oficial da rede de ensino a obrigatoriedade da temática da história da cultura afro-brasileira nas coleções de livros de história do Ensino Médio. A análise procurou observar a forma que as temáticas referentes à cultura africana e afro-brasileira foram apresentadas e distribuídas nesse material. A obrigatoriedade prevista na lei mencionada foi uma das premissas à validação do conteúdo desses livros. As obras foram aprovadas em 2010 pelo Fundo Nacional de Educação (FNDE) em parceria com a Secretaria de Educação Básica (SEB), do Ministério da Educação (MEC). No ano de 2011, essas obras foram encaminhadas às escolas da rede pública para que ocorresse a escolha do livro didático que foi adotado em 2012, para o próximo triênio.
\end{abstract}

Palavras-chave: História; Lei 10.639; Livro didático; PNLD.

\section{Patrícia de Freitas}

Doutora em História pela Universidade Federal de Santa

Catarina - UFSC - Brasil patidefreitas@gmail.com

\footnotetext{
Para citar este artigo:

FREITAS, Patrícia de. Avanços na inclusão da temática de história e cultura afro-brasileira e africana. PNLD Ensino Médio 2012 e a lei 10.639. Revista Linhas. Florianópolis, v. 15, n. 29, p. 379-394, jul./dez. 2014.
}

DOI: $10.5965 / 1984723815292014379$

http://dx.doi.org/10.5965/1984723815292014379 


\title{
Advances in the inclusion of the theme of history and African- Brazilian and African culture. PNLD Secondary Education Act 2012 and the 10,639
}

\begin{abstract}
The main point of this article discusses the application of law 10,639 which included the official curriculum of the school the compulsory subject in the history of African-Brazilian culture in the collections of history books of the school. The analysis sought to observe the way that topics related to African culture and African-Brazilian were presented and distributed these materials. The obligation under the law mentioned was one of the premises to validate the contents of these books. The projects were approved in 2010 by the National Education (FNDE) in partnership with the Department of Basic Education (SEB), the Ministry of Education (MEC). In 2011 these works were sent to public schools so happen to choose the textbook that was adopted in 2012, for the next triennium.
\end{abstract}

Keywords: History; Law 10,639; Textbook; PNLD. 


\section{Introdução}

A temática referente à cultura africana e afro-brasileira sempre esteve presente nos livros didáticos de história. Mas de que forma esse conteúdo foi apresentado? Mulheres, indígenas, africanos, afrodescendentes por muito tempo encenaram papéis muito específicos que não condiziam com suas vidas, com o seu cotidiano. A história há muito tem revisto essa questão. Recontando fatos, sob novos ângulos, dando voz àqueles que ficavam na coxia. O reconhecimento e a valorização da identidade desses grupos, no caso deste artigo, da história e da cultura dos afrodescendentes dependem do sucesso das políticas públicas do Estado. Da efetivação da lei 10.639, que torna obrigatório o ensino de história e cultura afro-brasileira na educação básica. A iniciativa deste texto é procurar analisar como esse conteúdo vem sendo trabalhado nas coleções didáticas de história, destinadas ao ensino médio das escolas públicas do Brasil.

\section{Histórico: a distribuição dos livros didáticos no Brasil}

A história dos livros no Brasil é tema que suscita uma ampla gama de análises, especialmente aqueles pesquisadores da área do ensino e da história da educação. Dos livros escolares do século XIX, aos livros didáticos do XXI, uma coisa é certa: esse seguimento da indústria do impresso tem se consolidado, ao longo do tempo, como o carro chefe da produção livresca. Ao analisar os livros escolares destinados às escolas primárias, secundárias e normais no Brasil, entre 1810 e 1910, Circe Bittencourt, destacou que, nesse momento, este material já avultava com a tiragem mais elevada, se comparada com a produção de livros em geral. Para a autora: "A circulação dos livros escolares superava todas as demais obras de caráter erudito, possuindo um status diferenciado" (BITTENCOURT, 2008, p. 83).

Segundo as estimativas do MEC (BRASIL, 2011a) e os últimos dados do Programa Nacional do Livro Didático - PNLD no ano de 2011 o governo federal investiu a quantia de R\$1.077.805.377,28. Na compra, avaliação e distribuição dos livros didáticos do PNLD 2011, 
que foram direcionados a toda a educação básica. ${ }^{1} \mathrm{O}$ montante gasto com esse material evidencia que a indústria do livro didático é um segmento em ascensão, conforme os programas desenvolvidos pelo PNLD são ampliados, renovados e acrescidos.

Ao trabalhar com temas relacionados a livros didáticos distribuídos nas escolas públicas brasileiras faz-se necessário abrir um parêntese sobre a história atual da institucionalização desse material no Brasil. O primeiro marco data de 1929, quando foi criado o Instituto Nacional do Livro (INL) que teve como objetivo legitimar e incrementar esta produção. A Comissão Nacional do Livro Didático (CNLD), de 1938, possuía a função de estabelecer uma legislação que além de regulamentar, também deveria controlar a produção e a circulação do livro didático. Ainda no governo de Getúlio Vargas, o decretolei $n^{\circ} 8.460$, de 1945, assegurava o que já havia sido regularizado pela lei anterior, incluindo o controle de importação do livro.

No ano de 1966, o MEC, em parceria com a Agência Norte-Americana para o Desenvolvimento Internacional (USAID), criou a Comissão do Livro Técnico e Livro Didático (Colted), que nesse mesmo ano distribuiu a cifra de 51 milhões de livros. Como é possível observar, foram várias as iniciativas que buscavam produzir, editar, coordenar e distribuir os volumes. A década de 1970 é marcada pela consolidação desta política, pelo Programa do Livro Didático, então coordenado pela Fundação Nacional do Material Didático (Fename). No decênio seguinte, o material escolar passou a ser distribuído pela Fundação de Assistência ao Estudante (FAE). Em 1985, foi criado o PNLD que além de distribuir livros didáticos, tinha como finalidade a melhoria da qualidade deste material e a formação de leitores.

O PNLD, em 1996, deu um importante passo, dando maior ênfase à questão pedagógica, criando uma comissão que passou a avaliar os livros que seriam adquiridos. No ano seguinte, o FNDE, assumiu a política do livro didático no país. Viu-se, a partir daí, uma incrementação na política de distribuição deste material. Foi criada uma série de

\footnotetext{
${ }_{1}^{1}$ Ainda segundo esses dados: "No ensino fundamental, o investimento foi de $\mathrm{R} \$ 893.003 .499,76$. Já o ensino médio contou com o investimento de $R \$ 184.801 .877,52$. Os professores de $6^{\circ}$ ao $9^{\circ}$ ano realizaram a escolha, sendo distribuídos livros a todos os alunos desse segmento em 2011. Os alunos de $1^{\circ}$ ao $5^{\circ}$ ano e os de ensino médio, receberam livros para reposição e complementação dos PNLDs 2009 e 2010. Ao todo, foram adquiridos 137.556.962 livros para atender a 29.445.304 alunos."
} 
medidas que ultrapassou a fronteira dos didáticos. O Programa Nacional Biblioteca da Escola (PNBE) ilustra bem esse incremento, ao distribuir materiais paradidáticos destinados às bibliotecas das escolas públicas de todo o país. Este tipo de distribuição já existia, mas nunca nesse volume e na qualidade do material que tem chegado às escolas. Ao lado de clássicos da literatura brasileira e livros de literatura infanto-juvenil, são distribuídas obras de referência que por muito tempo ficaram restritas às bibliotecas das instituições de ensino superior.

Em 2001, o PNLD, em conjunto com a Secretaria de Educação Especial (Seesp), ampliando a possibilidade de acesso aos portadores de deficiência visual estudantes de escolas públicas, passou a distribuir livros em Braille. Nesse mesmo ano, ampliou-se a distribuição de dicionários.

\section{Histórico: a distribuição de livros didáticos para o ensino médio}

Em 2004 foi implantado pelo FNDE, o Programa Nacional do Livro Didático para o Ensino Médio (PNLEM). A distribuição desse material, neste primeiro momento, ocorreu de forma gradativa. As regiões norte e nordeste receberam livros de matemática e língua portuguesa para os alunos da primeira série do ensino médio e, em seguida, além dessas duas disciplinas, também foram contempladas biologia, química e história de norte a sul do país, nas três séries do ensino médio. No ano de 2009, o programa incluiu as disciplinas de geografia e física. (BRASIL, 2008)

Em 2011 o PNLEM incluiu todas as disciplinas que compõem o componente curricular do ensino médio (com exceção da disciplina de artes) das escolas públicas brasileiras. E, pela primeira vez, os professores que lecionam biologia, filosofia, física, geografia, história, língua estrangeira (espanhol e inglês), língua portuguesa, matemática, química e sociologia tiveram a oportunidade de escolher os livros que serão utilizados neste triênio. Segundo dados do Ministério da Educação (BRASIL, 2011a), o orçamento 
para a compra desses livros e ainda para a reposição e a complementação dos livros didáticos do ensino fundamental foi de $R \$ 1,2$ bilhão.

As coleções dos livros didáticos de ensino médio, das disciplinas mencionadas no parágrafo anterior, chegaram às escolas da rede pública em 2011. Com exceção do estado de São Paulo, que se mantém fora das ações diretas do PNLD. E optou por receber a verba referente ao PNLD, selecionando por conta própria seus livros didáticos. Durante o primeiro semestre de 2011 foram avaliadas pelo corpo docente, coordenação pedagógica e direção o prazo limite estabelecido pelo MEC para o cadastro das obras escolhidas, que foi de 23 de maio a 12 de junho do corrente ano. Mas, antes de chegar às escolas, essas coleções passam por uma avaliação pedagógica, num convênio firmado entre o FNDE e universidades. Especialistas na área elaboram um catálogo que contém resenhas dessas coleções. Reunido, esse material formou o "Guia de livros didáticos: PNLD 2012: História” (BRASIL, 2011b), que é distribuído a todas as escolas. Em relação à referida disciplina, a instituição responsável pela avaliação foi a Universidade Federal de Santa Catarina e sua versão impressa não chegou até as escolas, de maneira que os professores, para recorrêla, deveriam acessar o site do MEC e baixar a versão em arquivo PDF Adobe.

Segundo o "Guia de livros didáticos: PNLD 2012: História", desta disciplina foram selecionadas 19 coleções que estariam disponíveis nas escolas para a consulta e escolha. No ato da escolha, o professor deve indicar a coleção de sua preferência e uma segunda opção, caso a primeira não esteja disponível. No caso específico das coleções de história, na escola onde a autora leciona chegaram 13 coleções. É importante constatar este fato visto que, no momento anterior às escolhas, ocorrem fatos que podem incentivar a seleção de determinada coleção, em detrimento de outra, que talvez nem cheguem até a escola.

O programa de distribuição do livro didático em si já constitui um evento de proporções gigantescas, em especial no que diz respeito ao valor do orçamento destinado à aquisição das obras e distribuição das mesmas. O envio do material ocorre através de um contrato firmado entre o FNDE e a Empresa Brasileira de Correios e Telégrafos (ECT), cobrindo um país de proporções continentais. A remessa das coleções causa euforia nas editoras mobilizando um verdadeiro exército que envolve especialistas 
dos mais variados. A escolha desse material é um evento de mercado, daí a necessidade de pensar esse momento levando em consideração as condições econômicas e sociais de produção de um compêndio escolar (MEDEIROS, 2006, p. 73-92).

Em vista disso, cabe destacar que durante o período que antecede a escolha dos livros didáticos existe todo um trabalho desenvolvido pelas editoras. Profissionais responsáveis pela elaboração das coleções conferem palestras por todo o país, divulgando o material. Evento que ocorre em hotéis de capitais, cujos convites chegam até as escolas. Funcionários destas empresas visitam os estabelecimentos de ensino e procuram conversar com os professores apresentando as vantagens de escolher determinada coleção. Brindes são distribuídos e existe ainda toda uma preocupação logística dessas editoras que possuem uma frente que entra em contato com as escolas, conferindo se o material da empresa chegou a seu destino. Logo, as editoras que possuem o maior número de filiais, profissionais disponíveis para a visitação e que conseguem conferir o translado do material, chegam à frente, ultrapassando editoras de pequeno porte que podem até oferecer um material didático de qualidade, mas não possuem o know-how do porte de editoras que se destacam nesse mercado de impresso.

\section{A lei 10.639 no PNLD ensino médio 2012}

As coleções de livros didáticos, antes de chegarem às mãos do grupo de especialistas avaliadores seguem todo um roteiro. Primeiramente, as regras são estabelecidas em um edital publicado no Diário Oficial da União. Lá consta uma série de recomendações estabelecidas pelo FNDE em conjunto com a SEB, do MEC. Então a editora inscreve suas coletâneas, sabedora dos critérios que as mesmas devem conter. Logo, os critérios comuns a todas as áreas, e no caso dos livros de história inscritos para o PNLD Ensino Médio 2012, devem atender aos critérios específicos para o componente curricular.

Cabe destacar os critérios comuns, que dão ênfase à necessidade das obras respeitarem a legislação, as diretrizes e as normas oficiais relativas ao ensino brasileiro, 
em especial aquelas estabelecidas para o ensino médio. Ao conjunto de leis, norma e diretrizes destaca-se: Constituição da República Federativa do Brasil; Lei de Diretrizes e Bases da Educação Nacional, e suas alterações introduzidas pelas Leis n 10.639/2003, $n^{\circ}$ 11.274/2006, $\mathrm{n}^{\circ}$ 11.525/2007 e n 11.645/2008; Estatuto da Criança e do Adolescente; Diretrizes Curriculares Nacionais para o Ensino Médio; Resoluções e Pareceres do Conselho Nacional de Educação, em especial, o Parecer CEB n 15, de 04/07/2000, 0 Parecer CNE/CP nº 003, de 10/03/2004, e a Resolução CNE/CP nº 01, de 17/06/2004 (2012, p. 12).

Conformes informações do PLND (BRASIL, 2011b) as obras devem estar pautadas nas discussões mais recentes, não compactuando com qualquer tipo de estereótipo, discriminação, bem como contemplar o caráter laico e autônomo do ensino publico brasileiro. Ao mesmo tempo, não poderá ser veiculada publicidade, propaganda de produtos, marcas ou de serviços comerciais.

As considerações evidenciadas neste artigo dizem respeito a 13 coleções de história (ALVES E OLIVEIRA, 2010). As análises realizadas estão focadas basicamente na forma que as temáticas referentes à cultura africana e afro-brasileira foram apresentadas e distribuídas, considerando a obrigatoriedade prevista na lei 10.639 e estabelecida como uma das premissas à validação do material. Importante lembrar que a temática indígena, conforme lei 11.645, e de gênero, são temas que necessitam de averiguação cuidadosa neste tipo de material, por isso não foram contempladas neste apontamento. Cabendo, a cada uma delas, estudos específicos.

O primeiro ponto observado faz menção a algo já observado pelo grupo de estudiosos que credenciou as coleções (ALVES; OLIVEIRA, p.18), que podem ser divididas em dois grupos: história integrada e história temática. Sendo que das 13 coleções apenas uma (MOCCELLIN; CAMARGO, 2010) pode ser considerada temática. A história integrada enquadra-se no que se definiu por quadripartismo francês (História Antiga, Medieval, Moderna e Contemporânea); já na obra organizada segundo a história temática, conteúdos estão organizados por temas que estruturam a abordagem histórica, levando em consideração múltiplos espaços e temporalidades. Verifica-se, nesta perceptiva de 
abordagem, um encadeamento cronológico na organização desses conteúdos ao longo dos volumes.

A perspectiva da história integrada prevaleceu nas coleções observadas (ALVES; OLIVEIRA, 2010). Em muitos desses livros, as temáticas relacionadas à África são encaixadas naqueles marcos eurocêntricos por ela definidos. A África, neste contexto, é apresentada como o continente onde tudo começou. Como se pode observar nos títulos, bastante condizentes: "África o começo de tudo" (SANTIAGO; CERQUEIRA; PONTES, 2010) "África, o berço da humanidade" (PEDRO; LIMA, 2010) "África o surgimento dos seres humanos" (CAMPOS; CLARO, 2010). Dentro dessa proposta, a temática relacionada à África aparece nas coleções no primeiro volume da coleção, no livro do $1^{\circ}$ ano do ensino médio em meio à temática da pré-história.

Acompanhando o mote dado pelas coleções que possuem o enfoque da chamada história integrada, percebe-se que ocorreu a inclusão dos reinos e impérios africanos ${ }^{2}$, fato que até então ficava restrito ao Egito. É evidente a gama de discussões que podem ser acompanhadas nessas coleções. Debates, releituras acadêmicas que finalmente chegam, em versões condensadas, nos compêndios do ensino médio. 0 continente passa a ser reconhecido pela sua dimensão territorial e, consequentemente, sua diversidade na cultura, no clima, no relevo e na geografia, dentre outras particularidades.

Este é o primeiro passo para desvincular a África daquela imagem distorcida. Há muito atrelada a leões, epidemias, choupanas na floresta e desertos. O pesquisador da cultura afro-brasileira, Henrique Cunha Jr. (CUNHA Jr., 2002, p. 57-72), ao analisar as principais dificuldades encontradas no ensino de questões pertinentes à história africana aponta como os preconceitos são adquiridos devidos ao que ele chamou de um "processo de informação desinformada sobre África." (CUNHA Jr., 2002, p. 58). A superação desta África construída com a ajuda de revistas de viagens e pela indústria cinematográfica será efetivada através de um ensino que prioriza a diversidade, o

\footnotetext{
${ }^{2}$ Segue alguns exemplos: Cuxe: o grande reino negro. In: BRAICK, Patrícia Ramos; MOTA, Myriam Becho. História das cavernas ao terceiro milênio. São Paulo: Moderna, 2010. p. 68. (1v. 96p.)
} 
multiculturalismo. Logo, cabe uma reformulação do material didático utilizado nas escolas, particularmente dos livros de história, geografia e língua portuguesa.

Em relação aos conteúdos de história do Brasil, percebe-se o mesmo fato, ou seja, temas clássicos aparecem como uma nova roupagem, acompanhando as discussões desenvolvidas especialmente nos cursos de pós-graduação. Ao lado de temas referentes à escravidão, alguns autores destacam a resistência africana e indígena. Africanos e afrodescendentes são chamados de "trabalhadores". Fato que parece banal, mas incute uma resposta positivada para todos aqueles que procuram nos manuais didáticos a história de seu povo. Por décadas, apregoou-se a ideia do negro cativo, escravizado que vivia em senzalas imundas e apanhava no tronco.

A escravidão foi uma realidade, a questão não é negá-la, mas retirá-la de uma condição que por muito tempo pareceu naturalizada. Assim como a ideia de samba, feijoada, ou "contribuições" no léxico. Até pouco tempo atrás, ainda era possível encontrar livro com meia página de informações acerca das contribuições de 'negros' e 'índios' à cultura brasileira, para encerrar, uma conta da junção das raças, somando: negro + branco = mulato; índio + negro = cafuzo; negro + índio = mameluco. E a criança que não se enquadrava nessa adição provavelmente ficava bem desesperada imaginando porque não estava contemplada nessas equações redutoras. As continhas servem para ilustrar tantas outras situações que contribuíram para ilustram quanto o sistema de ensino foi condizente com um currículo escolar que acabou reproduzindo práticas racistas, discriminatórias e preconceituosas.

Daí a importância de leis como a 10.639, de 09/01/2003 e 11.645, de 10/03/08 enquanto mecanismos de transformação que superem estereótipos de afro-brasileiros e indígenas já arraigados na cultura escolar brasileira. Existe avanço nas coleções de livros didáticos de história para o ensino médio. A África e os afro-descentes ganharam maior espaço e interpretações. Permanece ainda muita lacuna, espaço para muitos debates. Parece também que não há consenso quanto ao lugar deste continente, por tanto tempo relegado. No início, abrindo a pré-história? Nos boxes, em discussões afinadas com a academia? Em adendos, nos finais de capítulos? Talvez esse rebuliço seja pertinente, pois 
a confusão de temas parece fugir daquela divisão clássica (história antiga, média, moderna e contemporânea) que sempre norteou os livros de história.

É sempre bom lembrar que nesta divisão clássica, a África figurava apenas no capítulo dedicado ao Egito; o continente jamais foi incorporado de fato. O Egito é uma das civilizações antigas que mais chama a atenção e o interesse dos alunos. Mas, por muito tempo, sua história foi relacionada à África apenas na sua localização geográfica. Pouca ou nenhuma atenção foi dada à tez daquele povo, tão pouco as civilizações circunvizinhas. Como já foi mencionado, as coleções atuais já incluem algumas dessas discussões e acrescentam a existência de outras civilizações, como a dos Núbios, um dos povos que viviam na região do Sudão. Outros povos, entretanto, ainda precisam ser incorporados. Estudos têm destacado, nesta mesma região, os “(...) Impérios de Kerma, Kushes, Napata e Meroes. Fixados em regiões próximas têm importância histórica os Reinos da Etiópia" (CUNHA Jr., 2002, p. 68).

Cunha Jr. propõe uma cronologia para os estudos referentes ao continente africano. A meu ver, a proposta do estudioso pode servir de sugestão para os autores de livros didáticos. Segue a cronologia de autor:

A cronologia da história africana pode ter a seguinte composição:

1 - Aparecimento do Homo Sapiens na África - 10.000 A.C.

2 - Agricultura e criação no Vale do Nilo - 5.000 A.C.

3 - Os Faraós unificam o Estado Egípcio - 3.100 A.C.

4 - O Estado Kerma governa a Antiga Núbia no Sudão - 2.250 A.C.

5 - As dinastias Egípcias colonizam o Núbia - 1.570 A.C.

6 - Os Estados Kushes e Napatos se estabelecem no Sudão - 1.100 a 500 A.C.

7 - Fenícios fundaram a Capital em Cartago - 814 A.C.

8 - Os Estados Kushes da Núbia governam o Egito - 760 A.C.

9 - A tecnologia do Ferro é introduzida no Egito pelos invasores Assírios - 500 A.C.

10 - Reinos Núbios - 400 A.C.

11 - Civilização Nok na África Ocidental - 450 A.C.

12 - Os Gregos invadem o Egito - 332 A.C.

13 - Os Romanos invadem o Egito - 40 A.C. 
14 - Início do esplendor dos Reinos Axum na África Oriental - 0

15 - Expansão Islâmica no Norte Africano - 639

16 - Data aproximada da construção do Zimbábue - 700

17 - Ocupação de Gana pelos Almoravides - 1.076

18 - Fundação do Império Monomotapa na África Austral - 1.200

19 - Início do Império do Mali - 1.235

20 - Fundação do Reino do Congo - 1.240

21 - Início do Império Songai - 1.400

22 - Os Portugueses vencem os Mouros e tomam Ceuta no Norte Africano - 1.415

23 - Fundação do Reino Luba na região do Rio Congo - 1.420

24 - A presença constante de mercantes portugueses no Rio Senegal - 1.445

25 - Estabelecimento do tratado comercial entre Reinos da África Ocidental e os Portugueses - 1.456

26 - Tratado de Alcáçovas entre Espanhóis e Portugueses que permite aos Portugueses a introdução de escravizados Africanos na Espanha - 1.475 .

27 - Chegada dos Portugueses ao Congo - 1.484

28 - Conversão do Rei do Congo ao Catolicismo - 1.491 (o Catolicismo já havia penetrado na Etiópia 400 anos antes)

29 - Destruição do Império Songai - 1.591

30 - Portugueses invadem Angola transformando o Reino em Colônia - 1.575

31 - O Reino do Congo é dominado pelos Portugueses - 1.630

32 - Chegada dos Ingleses como invasores e colonizadores na África do Sul - 1.795

33 - Início das Campanhas Militares de Chaka-Zulu - 1.808

34 - Consolidação do Domínio Europeu na África - 1.884/1.885 (CUNHA Jr., 2002, p. 69-71).

Cabe destacar que das 13 coleções analisadas, uma das estudiosas apresentou$\mathrm{se}^{3}$ como autora de publicações didáticas e paradidáticas na área da temática africana. A presença de um especialista pode contribuir para a elaboração dos materiais distribuídos pelo Ministério da Educação. Seguindo todas as recomendações da legislação vigente é

\footnotetext{
${ }^{3}$ Ver na contra-capa de: CAMPOS, Flavio de; CLARO, Regina. A escrita da história. São Paulo: Edições Escala Educacional, 2010. p. 32 (1v. 96 p.)
} 
necessário questionar formatos, temas, relações que são atribuídas à história e cultura afro-brasileira, assim como a indígena.

Mas, em relação à confecção deste material, Circe Bittencourt lembra que o livro didático é uma mercadoria que obedece e sofre interferências (BITTENCOURT, 2004, p. 71). Sua organização corresponde a inúmeros profissionais e as coisas não saem exatamente do jeito que o autor imagina. Aliás, ele é apenas mais um na linha de produção da indústria cultural que impõe e determina a forma de organização (BITTENCOURT, 2004, p. 73). Ainda é preciso considerar o uso e a leitura realizada por professores e alunos. Professores que possuem liberdade para utilizá-lo da forma que achar necessária e proveitosa, pulando ou selecionando determinados conteúdos. Daí a importância fundamental na formação e capacitação dos professores que atuam no ensino fundamental e médio para o efetivo cumprimento da legislação que determina o ensino da história e da cultura afro-brasileira.

De modo geral, ocorreram avanços significativos na qualidade, quantidade e apresentação de conteúdos relacionados à história da África e afro-brasileira. Aos poucos, ocorre uma revisão de marcos eurocêntrico, de abordagens pejorativas, visões preconceituosas e tratamentos estereotipados. De perspectivas simplificadoras que apresentam grupos historicamente excluídos como vitimas da história ou ainda como entidades genéricas, cujas particularidades de origem, de língua, de religiosidade, dentro outras não foram reconhecidas.

Cabe sugerir ao Ministério da Educação a participação de autores especialistas em todo o processo que vai da elaboração à análise do material didático que será distribuído para alunos do ensino fundamental e médio, cabendo a participação efetiva de estudiosos das áreas de gênero, raça e etnia na composição deste material Profissionais vinculados aos programas de pós-graduação das universidades federais, boa parte bolsistas de instituições de fomento financiados pelo próprio ministério.

Mas a efetivação da lei só ocorrerá quando a educação básica for considerada prioridade pelo governo. As leis 10.639, 11.645, assim como a 11.738, que instituiu o piso 
salarial profissional nacional para os profissionais do magistério público da educação básica, promovem, através do seu conteúdo, profundas transformações no currículo e na carreira dos professores. Mas existe um paradoxo entre a sanção de uma lei e os modo que a mesma pode ser burlada: o governo que promove o avanço é o mesmo que negligencia a necessidade de um plano de carreira que, além de assegurar um salário digno, garanta carga-horária que contemple planejamento, estudo da legislação vigente, capacitação continuada, utilização das novas tecnologias, entre outros.

Setores da administração pública de todas as esferas, universidades públicas e particulares precisam estabelecer, de modo eficaz e permanente, um diálogo entre a formação do professor e a educação básica. Então, evidenciar o modo como à temática africana é contemplada nos livros didáticos de história do ensino médio requer um olhar acurado sobre o assunto, e a educação brasileira, de um modo mais amplo. $O$ fato é que há 10 anos a lei 10.639, que tornou o ensino de história e cultura afro-brasileira nas escolas das redes pública e privada do ensino fundamental e médio, foi implantada. Ao que tudo indica, ainda não é possível avaliar sua eficácia, visto que em torno da questão que envolve a obrigatoriedade de um componente curricular e o saberes docentes exista outra lacuna. A temática é ampla, mas podemos comemorar neste primeiro decênio a esperança da construção de um ensino de qualidade, entendido como uma proposta que reconheça, respeite e conceba uma política educacional antidiscriminatória e antirracista. 


\section{Referências}

ALVES, Alexandre; OLIVEIRA, Letícia Fagundes de. Conexões com a história. São Paulo: Moderna, 2010. (1v. 119 p.; 2v. 104 p.; 3v. 96 p.)

BERUTTI, Flávio. Caminhos do homem. Curitiba: Base Editorial, 2010. (1v. 320 p.; 2v. 272p.; 3v. 272p.)

BITTENCOURT, Circe. Livros didáticos e saber escolar: 1810-1910. Belo Horizonte: Autêntica, 2008. 239p.

BITTENCOURT, Circe. Livros didáticos entre textos e imagens. In: BITTENCOURT, Circe (Org.). O saber histórico na sala de aula. São Paulo: Contexto, 2004. p. 69-90.

BRAICK, Patrícia Ramos; MOTA, Myriam Becho. História das cavernas ao terceiro milênio. São Paulo: Moderna, 2010. (1v. 96 p.; 2v. 144 p.; 3v. 96 p.)

BRASIL. Ministério da Educação e Cultura. Fundo Nacional de Desenvolvimento da Educação. Módulo programa do livro - PLI. Brasília: MEC, FNDE, SEED, 2008. p. 26

BRASIL. Ministério da Educação e Cultura. Fundo Nacional de Desenvolvimento da Educação. Guia de livros didáticos PNLD 2012. Brasília, 2011b. Disponível em:

http://www.fnde.gov.br/index.php/pnld-guia-do-livro-didatico. Acesso em: 19 jun. $2011 a$

BRASIL. Ministério da Educação e Cultura. Fundo Nacional de Desenvolvimento da Educação. Programa Nacional do Livro Didático. Brasilia, 2011. Os últimos números do PNLD. Disponível em: <http://www.fnde.gov.br/index.php/programas-livro-didatico>. Acesso em: 18 jun. 2011 a

CAMPOS, Flavio de; CLARO, Regina. A escrita da história. São Paulo: Edições Escala Educacional, 2010. (1v. 96 p.; 2v. 88 p.; 3v. 88p.)

COTRIM, Gilberto. História global. São Paulo: Saraiva: 2010. (1v. 80 p.; 2v. 80 p.; 3v. 80 p.) CUNHA JUNIOR, Henrique. A história africana e os elementos básicos para o seu ensino. In: LIMA, Ivan Costa; ROMÃO, Jeruse. (Orgs.) Negros e currículo. Florianópolis: Atilènde, 2002. p. 57-72.

FARIA, Ricardo de Moura; MIRANDA, Mônica Liz; CAMPOS, Helena Guimarães. Estudos de história. São Paulo: FTD, 2010. (1v. 80 p.; 2v. 80 p.; 3v. 80 p.)

MEDEIROS, Daniel Hortêncio de. Manuais didáticos e formação da consciência histórica. Educar, Especial, 2006.

MOCELLIN, Renato; CAMARGO, Rosiane de. História em debate. São Paulo: Editora do Brasil, 2010. (1v. 263p.; 2v. 288p.; 3v. 288p.)

NARITA, Felipe Ziotti. Livros didáticos na formação do Brasil. Revista Espaço Acadêmico, n. 108, maio. p. 182-184, 2010.

NOGUEIRA, Fausto Henrique Gomes; CAPELLARI, Marcos Alexandre (Orgs.). História: Ser protagonista. São Paulo: Edições SM, 2010. (1v. 95 p.; 2v. 104 p.; 3v. 95 p.) 
PEDRO, Antônio; LIMA, Lizânias de Souza. História sempre presente. São Paulo: FTD, 2010. (1v. 80 p.; 2v. 80 p.; 3v. 79 p.)

PELLEGRINI, Marco; DIAS, Adriana Machado; GRINBERG, Keila. Novo olhar história. São Paulo: FTD, 2010. (1v. 112 p.; 2v. 128 p.; 3v. 128 p.)

SANTIAGO, Pedro; CERQUEIRA, Célia; PONTES, Maria Aparecida. Por dentro da história. São Paulo: Edições Escala Educacional, 2010. (1v. 128 p.; 2v. 96 p.; 3v. 104 p.)

VAIFAS, Ronaldo et al. História. São Paulo: Saraiva: 2010. (1v. 40op.; 2v. 368p.; 3v. 463p.)

VICENTINO, Cláudio; DORIGO, Gianpaolo. História geral e do Brasil. São Paulo: Scipione, 2010. (1v. 248p.; 2v. 336p.; 3v. 304p.) 